\title{
CULTURA CORPORAL E PENSAMENTO SOCIAL BRASILEIRO: MODELO CONTEMPORÂNEO E DIALÉTICAS
}

Thiago Elias Merlo

Sérgio Ferreira Tavares

\section{Resumo}

A cultura corporal e o pensamento social brasileiro têm paradigmas pertinentes. Ambos se norteiam nas particularidades da sociedade e nos acontecimentos históricos e contemporâneos. Este ensaio reflete sobre estes acontecimentos (espontâneos na maioria dos casos) através da ótica da cultura brasileira, especialmente da cultura corporal. João Paulo Subirá Medina é um dos autores que oferece modos peculiares de transcender o pensamento superficial de cultura corporal, para que se construa a criticidade tão necessária para o entendimento das questões sociais. Utilizando a mecânica de compressão de Medina, avaliaremos as dialéticas da cultura corporal contemporânea e os principais autores que compõem o pensamento social brasileiro: Gilberto Freyre, Roberto DaMatta, Sérgio Buarque de Holanda e Jessé Souza.

\section{Palavras-Chave:}

Cultura corporal; Sociologia; Antropologia; Filosofia.

\section{CORPORAL CULTURE AND BRAZILIAN SOCIAL THOUGHT: CONTEMPORARY MODEL AND DIALETCS}

Thiago Elias Merlo

Sérgio Ferreira Tavares

Núcleo de Educação Física/UCB

\begin{abstract}
The corporal culture and the brazilian social thought have pertinent paradigms. Both are guided in the particularities of the society and in the historical and contemporaries events. This rehearsal reflects on these events (spontaneous in the majority of the cases) through of the optics of the brazilian culture, especially of the corporal culture. João Paulo Subirá Medina is one of the authors who offers peculiar ways to transcend the superficial thought of corporal culture, so that later constructs the necessary critique for the agreement of the social questions. Using the mechanics of compression of Medina, we will evaluate the dialectics of the contemporary corporal culture and the main authors who compose the brazilian social thought: Gilberto Freyre, Roberto DaMatta, Sergio Buarque de Holanda and Jessé Souza.
\end{abstract}

\section{Key-Word:}

Corporal culture; Sociology; Anthropology; Philosophy. 


\section{Introdução}

A simbiose entre cultura corporal contemporânea e sociedade brasileira é fascinante. A riqueza de elementos culturais presentes nos corpos dos brasileiros ultrapassa a própria existência: transcende a materialidade terrena e nos coloca em patamares diferenciados dos outros animais. As modificações da natureza a favor da existência humana corroboram para as discussões filosóficas sendo muitas delas foco de dialéticas que advém da pré-história até a contemporaneidade. A sobrevivência da raça caracteriza-se não somente pela agregação em conjuntos sociáveis possuidores de elementos burocráticos pré-definidos, mas da capacidade indelével de desenvolvimento tridimensional das habilidades humanas. Essa tridimensionalidade é mais do que uma visão sociológica em três ângulos: esse termo é utilizado para exemplificar uma observação globalizada dos movimentos sociais ininterruptos tendo seu fim em si próprio.

As habilidades humanas próprias à modificação da natureza, entre outras composições, geram um elemento identificador de sociedade: a cultura. Piaget definiu a cultura como um produto de experimentações sociais, muitas delas geradas a partir de movimentos sociais antigos e pertencentes à determinada sociedade. Conclui-se que ninguém produz cultura se não houver um processo de aceitação, agregação e assimilação do movimento social de todos os envolvidos na simbiose de ação social e elemento social. Imaginemos que espontaneamente um mito se tornou presente num determinado grupo social. Este mito traz consigo características assustadoras que são passados de geração em geração. Quando este mito, por mais infundado que seja, penetra nos imaginários sociológicos, este acontecimento caracterizou o conceito de cultura. As sociedades, periféricas ou não, dispõem de elementos culturais bastante característicos sendo que a ciência social de cada país tem refletido sistematicamente acerca dessas questões. A maior parte dessas reflexões direciona o foco para o processo desenfreado de globalização que sobrepõe culturas dominadas em favor as culturas dominantes e da disseminação do regime neoliberal, financiador das políticas que consomem e extinguem as culturas de um povo. Para exemplificação, vejamos o aparecimento da festa de "Halloween" e "Thanksgiving Day" (Dia de Ação de Graças) no Brasil que não têm nenhum elemento de embasamento que sustentam o aparecimento de ritos anglo-saxônicos.

A cultura corporal é subproduto de acontecimentos culturais globais. A visão do corpo como elemento de expressividade cultural é abertamente discutida na obra "O brasileiro e seu corpo" de Medina (2005a). O autor remonta os conceitos de indisponibilidade corporal e aborda as modificações para um corpo presente, elaborador, receptor e emissor de cultura. Medina transcende estas definições reducionistas e na 
sua visão, o corpo é um elemento de dominação, sendo ele dominado ou dominador. A ótica de classe social elaborada por Marx permea esta visão de corporeidade.

E para montarmos as dialéticas a favor de vários ângulos, confrontaremos a cultura corporal dos brasileiros e os principais pensadores sociais do Brasil. Freyre (1981) foi um dos primeiros a comentar como o corpo pode se tornar um condutor cultural. Freyre comenta a sociedade patriarcal do início do século XX e como os novos elementos culturais se apresentam. DaMatta (1981) vê os membros da sociedade brasileira segregados por indivíduos e pessoas que mostram através do conflito como o corpo e a cultura brasileira se impõem. Holanda (1936) discutiu o corpo de uma maneira singular: através da cordialidade. Holanda acredita que mesmo o Brasil possuindo o Estado burocratizado, os elementos de cordialidade e emoção não se desvinculam do corpo do brasileiro. Souza (2005, p. 2) talvez seja o autor com as concepções mais próximas de João Paulo Subirá Medina (2005). Souza explica o comportamento social brasileiro (e a cultura corporal a reboque) como conseqüência de status de sociedade periférica, sempre absorvendo culturas que não são genuinamente nacionais.

Com este enfoque, trataremos a cultura corporal sobre essas óticas de autores de épocas distintas.

\section{A cultura corporal por uma nova ordem social}

Os modelos de sociedade pela ótica da cultura corporal brasileira são ricos em conceitos e eventualmente díspares. Foram traçadas avaliações do corpo brasileiro através da literatura, das artes, da cultura, das ciências e discuti-se como este corpo interage com os movimentos desenvolvimentistas sociais, traçando paralelos da especificidade cultural. São díspares, pois a marca do processo colonizador europeu fica estampada nas ações, nas vestimentas, nos traços físicos, gerando causa e efeito, se é que podemos abordar o trato das coisas sociais com tanta objetividade. Das regiões do Brasil, cada uma apresenta características marcantes, pouco breves e unas, não eqüidistantes da cultura, marca fiel de identidade do país. Um dos pioneiros a abordar estas marcas sociais brasileiras no início do século XX foi Gilberto Freyre.

O corpo é registro vivo das mudanças sociais e Freyre em "Sobrados e Mucambos: a decadência do patriarcado rural e desenvolvimento do urbano" disserta sobre as mudanças da sociedade e ressalta como o corpo é resultado das faces aduaneiras da sociedade vigente. A maneira peculiar de distinção social era, antes de qualquer coisa, pela expressividade corporal. A fragilidade econômica entre as classes dominadas comparativamente as classes dominantes, ressaltava o quanto difícil era romper com os 
grilhões que separavam a liberdade consolidada, da abolição da escravatura e com a dialética da libertação social, advinda com a aquisição de meios sólidos de inclusão social.

O corpo que trabalha não é mais o do escravo. O corpo-dominador muda de postura, mas não de ótica: continua a dominar. Se a abolição da escravatura condicionasse no aparecimento de uma nova era para o dominado, saberíamos que o corpo-dominado sentiria os efeitos da liberdade, mas o ocorrido foi que o corpo-dominador, na insurgência da classe social proletariada, utilizou o próprio conceito capitalista para sistematizar uma nova "aliança desenvolvimentista burguesa".

Florestan Fernandes $^{2}$ reflete a respeito dos corpos-dominados e marginalizados da abolição da escravatura: "Em vez de ser projetada, em massa, nas classes sociais em formação e em diferenciação, viu-se incorporada à 'plebe', como se devesse converter-se numa camada social dependente e tivesse de compartilhar de uma 'situação de casta' disfarçada. Daí resulta que a desigualdade racial manteve-se inalterável, nos termos da ordem racial inerente à organização social desaparecida legalmente, e que o padrão assimétrico de relação racial tradicionalista (que conferia ao 'branco' supremacia quase total e compelia o 'negro' à obediência e à submissão), encontrou condições materiais e morais para preservarse em bloco".

Caso tratássemos o corpo-marginal como elemento-chave de entendimento da sociedade patriarcal, concluiríamos que marginais seriam todos os elementos sociais, sendo eles de classe dominante ou não. De certo modo, todos se marginalizaram porque o processo de adaptação à nova ordem social mazelou o modelo vigente e imperativo. Sabemos que os maiores mazelados foram os corpos-dominados porque do antigo tipo de dominação de corpo, sem lazer ou mesmo respeito, todo o formato de dominação se manteve, mudando da chibata e tronco para o modelo capitalista e liberal.

\section{O indivíduo, a Pessoa e a Cultura Corporal}

A cultura corporal se manifesta de acordo com o perfil das sociedades. Isso é fato. Por isso as manifestações culturais, inclusive as manifestações de cultura corporal, podem ser qualificadas e classificadas de acordo com o perfil de sociedade que estamos observando. As sociedades desenvolvidas possuem expressões culturais dos antigos povos que ali habitavam e se mantiveram. É o caso da

\footnotetext{
${ }^{1}$ Fernando Henrique Cardoso é sociólogo que dedicou parte de seus estudos a área econômica. Este termo foi cunhado de "Brasil: Tempo Modernos", coletânea promovida por Furtado (2005, p. 75).

${ }^{2}$ Florestan Fernandes é sociólogo e foi orientador de Fernando Henrique Cardoso. Dedicou seus estudos na esfera social, promovendo dialéticas sobre socialização nas questões de raça brasileira. (FURTADO, 1997, p. 113.)
} 
Inglaterra que mantém atualmente alguns ritos da cultura celta. As sociedades periféricas, principalmente as latino-americanas, possuem características culturais muito próximas, entretanto cada país absorveu a cultura européia de modo distinto, pois o colonizador interagiu com a cultura do colonizado e vice-versa. No caso do Brasil, nossa diversidade cultural foi mais intensa que os demais países sul-americanos, pois:

1) o processo de colonização foi mais complexo já que Portugal, Espanha, Holanda, França e mais tarde Inglaterra desembarcaram no país com seus hábitos e costumes;

2) houve interação da cultura indígena as práticas européias;

3) houve interação com a cultura africana anos depois e

4) a extensão territorial brasileira contribuiu para propagação de cultura.

Após a consolidação de todos estes pontos, estabeleceu-se o conceito da individualidade, pois desde da vinda da Família Real com Dom João VI, instituiu-se o Estado Brasileiro de acordo com o modelo teórico de Max Weber que se baseava, antes de tudo, na burocratização do Estado, fazendo com que o respeito e obediência aos representantes fossem peças-chaves de desenvolvimento de uma nação. Os resultados práticos são instituições governamentais mais sólidas e de gerenciamento conciso do aparelho estatal. Conforme o Estado Brasileiro se consolidava, a visão a partir da individualidade também acompanhava os rumos da história. Como a construção dessa sociedade sofreu solavancos sociais como as invasões francesas na região sudeste e holandesas na região nordeste, a abolição da escravatura, a queda do Império, o início da República, os reflexos nos cidadãos foram percebidos. O que se estabeleceu foi um modelo híbrido de sociedade que DaMatta (1981) classifica como sociedade semitradicional. Semitradicional porque trabalha conjuntamente com o conceito de sociedade com individualidade e pessoalidade nas dramatizações sociais.

A individualidade e pessoalidade presentes na sociedade se alternam nessas dramatizações de maneira muito peculiar. A alternância mais comum é através da tensão, do conflito, dos ritos e mitos ${ }^{3}$. No caso da cultura corporal, o evento social que melhor explica a questão do rito é o carnaval. O corpo-marginal que advém de classe social desfavorecida, no carnaval ornamenta o seu corpo para o "brincar". Entretanto este panorama simplista de brincadeiras e ludicidades não explicam a alternância da individualidade para a pessoalidade. Teoricamente o corpo-marginal é tão individualista e individualizado quando o corpo que expropria as forças dos membros da classe desfavorecida, só estando sobre condições do controle do

\footnotetext{
${ }^{3}$ Roberto DaMatta (1981) desenvolve seu pensamento sociológico/antropológico a partir da classificação do termo "rito" e "mito" que nada mais são do que referências a comportamentos coletivos seguidos de um movimento social expressivo. Exemplo: paradas militares, carnaval, funerais, entre outros.
} 
capital. Mas é no carnaval que a individualidade se extingue e pessoalidade hierarquizada aparece nas fantasias e nos ritos carnavalescos. Os corpos-marginais que outrora foram demasiadamente explorados, no carnaval ocupam posições privilegiadas como reis, rainhas, mestres-salas, porta-estandartes, fazendeiros e super-heróis. Enquanto os corpos-dominadores se vestem como colombinas, pierrôs, palhaços e mendigos, signos das discrepâncias sociais.

Os signos que qualificam as discrepâncias sociais já estão em debate pelos principais pensadores sociais brasileiros por anos. Carpeaux ${ }^{4}$ (1977) tratando de cultura brasileira através da literatura, escreve em seu artigo que os mitos e ritos sociais são, entre outras coisas, feitos para separar as classes detentoras de status social privilegiado das classes menos favorecidas, fazendo assim a marginalização do corpo através da cultura, ferramenta esta apropriada ao sentido de integração social:

[...] Mas podem existir - e existem na América Latina - grupos que usam atividades intelectuais e literárias para manter seu status social entre as classes. Um grupo desses já existia no Brasil da época colonial: homens letrados, padres, juízes, advogados, funcionários subalternos da Administração Públical que, não sendo escravos nem latifundiários escravocratas, não tinham situação bem definida dentro de má hierarquia social composta só daquelas duas classes. Mas sabiam defender-se. Os poetastros da época colonial portuguesa que forjaram encômios rimados a governadores, bispos e capitães-mores (os generais de então) para arrancar a esses mecenas um cargo rendoso ou uma pensão ou mesmo só uma esmola[...]. (CARPEAUX, p. 165, 1977).

Talvez as reflexões de DaMatta (1981) possam explicar a frase do carnavalesco Joãozinho Trinta: "Quem gosta de miséria é intelectual. Pobre gosta é de luxo!".

\section{A cordialidade nas relações de cultura corporal}

A obra de Holanda (1936) tem similaridades muito interessantes com os autores supracitados. Holanda acredita na influência do nosso passado hibérico formulando comportamentos únicos na América Latina, na composição da sociedade contemporânea iniciado pelo patriarcado rural, no aparecimento do aparelho do Estado Brasileiro instituindo as relações burocráticas onde o coletivo é administrado por representantes majoritários dos grupamentos sociais pré-concebidos. A última característica das dissertações e dialéticas de Sérgio Buarque de Holanda provém dos estudos a obra de Max Weber (18641920) que contribuiu para o pensamento de Estado hierarquizado, definindo claramente as atribuições sociais e administrativas de cada grupamento social.

Uma das linhas mais interessantes abordadas por Holanda (1936) é a formulação das relações interpessoais entre cidadãos e Estado Brasileiro. De acordo com esta linha, os cidadãos não conseguem

${ }^{4}$ Otto Maria Carpeaux foi jornalista e sociólogo. Desenvolveu sua linha de escrita na crítica a literatura e política. 
(ou não querem conseguir) identificar na instituição o objeto de representatividade de seus anseios enquanto membros da sociedade civil organizada. Acaba-se na maioria das vezes, na personalificação do Estado através de seu representante legal, algo de difícil compreensão para cidadãos de sociedades modernas como os Estados Unidos. Um exemplo clássico é a figura do despachante público que, entre outras atividades, promove a intermediação dos cidadãos aos serviços públicos, ou seja, a figura personalizada do Estado Brasileiro por um promovido qualquer.

Esta característica da sociedade brasileira é vista com maus olhos por Holanda, pois a cultura da personalificação não promove o avanço da sociedade, caracterizando uma certa imaturidade social. Em outras palavras, poderemos refletir que a cultura da personalificação é produto das características da cultura corporal que valoriza a expressividade dos gestos, dos atos e da presença dos envolvidos. Talvez seja esta a explicação para que membros de classes sociais tão mais avantajadas tolerem pacificamente a presença destas discrepâncias a sua vida cotidiana, pois acreditam que, mesmo havendo os abismos sociais, é melhor que estejam a vista para seu controle e opressão.

Outro aspecto da cultura do brasileiro e suas características de personalização dos mitos são através da religiosidade. Os brasileiros e os filipinos talvez sejam os povos que melhor traduzam a expressividade da cultura corporal religiosa entoando suas afirmações e convicções. A cultura corporal religiosa é demonstrada na devoção exacerbada aos santos - e alguns casos de sincretismo, aos orixás travestidos de santos - no pagamento de promessas e, principalmente, nas autopunições. Sérgio Buarque de Holanda inclusive cita a utilização do sufixo "inho" aos santos para, além de personificar uma figura sacra, diminuir as distâncias hierárquicas previamente instituídas, dando um ar de intimidade desnecessária.

A cultura corporal religiosa é, sobretudo a cultura do corpo-marginal. Corpo este que sofre as mazelas da vida cotidiana e para atenuar as dores da contemporaneidade, busca na religião o afago que a vida não lhe proporciona. É de interesse desse corpo-marginal que as marcas da promessa a serem pagas permaneçam em seu corpo dilacerado, fazendo assim uma espécie de qualificação cruel da sua fé, na esperança de dias melhores. Ou seja, mantém-se um ciclo vicioso, pois o corpo-marginal oferece-se a imolação quando imolado está a tempos. A reflexão está em saber se a personalificação dos mitos se monta pela dialética do modelo capitalista ou se o modelo capitalista quem leva a personalificação dos mitos para controle e administração social. 


\section{Sociedades Periféricas Para Cultura Corporal}

A análise critica das sociedades ditas periféricas nos remete a conclusões instigantes, sobretudo pelo ponto de vista social. Embora as distinções sociais latino-americanas sejam alvo de interligação histórica entre os povos, as similaridades acrescentam conhecimentos sólidos as dialéticas promovidas para entendimento da formação cultural. Jessé Souza é um intelectual que tem buscado explicar em seus materiais acadêmicos e científicos, as respostas para comportamentos diferenciados dos latinoamericanos na comparação as sociedades européias e asiáticas.

Em primeira instancia, o que Souza (2005) busca como explicação ao comportamento social do brasileiro é a complementação de pensamentos previamente instituídos no cenário sociológico e antropológico brasileiro, revisando criticamente os principais autores dessa área, tendo como exemplo Freyre (1981), Faoro (1958), Holanda (1936) e especialmente DaMatta (1981). Souza dispôs seus pensamentos de modo bastante crítico, mas especialmente corroborando com a ótica do individuo e pessoa nas dramatizações sociais brasileiras, já que ele acredita que fatores alheios à ordem social possam influenciar o modelo cosmopolita de comportamento.

Esses fatores alheios à ordem social - mas não dissonantes - tornam-se arcabouços das dramatizações sociais, influenciando assim os aspectos culturais. Souza (2005) acredita que os modelos políticos aplicados na América Latina (sociedades periféricas) pelas potências mais desenvolvidas influenciou significativamente a formação da sociedade, gerando culturas peculiares. Durante quase todo século XX, os modelos políticos sugeridos pelas grandes potências propagaram regimes totalitários em quase todos os países, alimentando os imaginários sociológicos através do medo e assim mecanizar as reações dos cidadãos. Na verdade a complementação da ótica do conflito de DaMatta gera uma dialética a Souza (2005): a individualidade e personalização sociais existem, mas não somente como foram citados por DaMatta (1981). Os métodos de gestão políticas presentes durante o século XX contribuíram para composição dos elementos de tensão e conflito presentes das relações sociais.

Os elementos culturais se apresentam conforme este imaginário sociológico se permea nas relações sociais, fazendo com que os corpos citados por Medina (2005) fiquem expostos a apreciação crítica. Conforme estes corpos se posicionam socialmente e trazemos para o diálogo o pensamento das sociedades periféricas, entenderemos melhor o processo de dominação, o processo do 
dominado/marginalizado, pois quando a política e capital se aproximam da área social observamos quais desses elementos se interligam e se separam no processo de formação da sociedade e de cultura.

\section{Conclusão}

As vertentes de estudo sobre cultura, especialmente sobre cultura corporal demonstram a riqueza de detalhes que este assunto dispõe. Os módulos de pensamento social foram discutidos de forma sucinta tendo como objetivo maior abordar as relações de corporeidade do Brasileiro. Nos meios de comunicação, nos lares e em todos os grupos sociais, de alguma forma a cultura corporal foi assunto de reflexões gerando opiniões. Afinal quem nunca pensou e repensou uma festa cultural interagindo com sua própria forma cotidiana de observar a vida?

No início do século XX, era o próprio corpo que respondia a qual classe social o cidadão pertencia. As vestimentas, a maneira de andar, de falar, de dançar, de costurar as relações interpessoais expunha o interlocutor a relacionar-se com seu meio social. Através dos mitos e ritos é que observamos o corpo por diversos sub-aspectos: no carnaval com a inversão de papéis sociais entre seus participantes; na parada militar como afirmação da hierarquização social; no velório que normaliza as dramatizações sociais e no futebol, que retém num único momento todas essas reações as relações sociais. Nesse momento a marginalização do corpo, ora se expõem com toda força, ora se retrai no modelo de opressão. Vimos como o modelo de cordialidade/passionalidade pode influenciar diretamente na administração de grupo social, especialmente os grupos com modelos de gestão estatal bem definidos, caso do Brasil. E ainda o nível de influencia que a política e seus respectivos modelos influenciam a elaboração de cultura corporal nas sociedades classificadas como periféricas.

Logo a percepção das reflexões é que a cultura corporal, influenciada pelos cidadãos e os cidadãos influenciados por diversos fatores externos, engrandecem o modelo de aparecimento, consumo e distribuição de cultura por todo país. Embora as reflexões possam nos levar ao um passado, presente e futuro doloroso sobre os oprimidos do modelo político adotado, tudo se embasa na pluralidade cultural, essa sim verdadeira função existencial da cultura e que nos distingue dos demais.

Passado as reflexões sobre pensamento social brasileiro e cultura corporal, abramos espaços para a interligação de cultura corporal com o lazer, a prática física, a prática pedagógica e outras linhas de 
entendimento para que a criticidade seja o pensamento que nasça das mentes ávidas por cultura e conhecimento, formando novas dialéticas para Educação Física na sociedade.

\section{Referências}

ARAÚJO, A. C. Biblioteca Virtual Gilberto Freyre.1999. Disponível em: $<$ http://prossiga.bvgf.fgf.org.br/portugues $>$. Acesso em: 24 jan. 2006.

HOLANDA, S. B. de. S. Raízes do Brasil. Rio de Janeiro: José Olímpio, 1936.

. Sérgio Buarque de Holanda - 100 Anos. Disponível em: <http://www.unicamp.br/siarq/sbh>. Acesso em: 06 mar. 2006.

CASTELlANI FILHO, L. Educação Física no Brasil: A história que não se conta. 4. ed. Campinas: Papirus, 1995.

BRASIL. Ministério da Ciência e Tecnologia. C\&T Jovem - Roberto DaMatta. Distrito Federal. Disponível em $<$ http://ctjovem.mct.gov.br/index.php?action=/content/view\&cod_objeto=10338>. Acesso em: 30 jan. 2006.

DAMATTA, R. Carnavais, Malandros e Heróis. 2. ed. Zahar, 1981.

FAORO, R. Os donos do poder. Porto Alegre: Globo, 1958.

FREYRE, F. G. Fundação Gilberto Freyre. Disponível em: <http://www.fgf.org.br>. Acesso em: 24 jan. 2006.

FREYRE, G. Sobrados e Mucambos: a decadência do patriarcado rural e desenvolvimento do urbano. Rio de Janeiro: José Olympio, 1981.

FURTADO C. Brasil: Tempos Modernos. 2. ed. Paz e Terra, 1977.

GHIRALDELli JR, P. Educação Física Progressista: A Pedagogia Crítico-Social dos Conteúdos e a Educação Física Brasileira. 8. ed. São Paulo: Loyola, 2003.

MEDINA, J. P. S. A Educação Física cuida do corpo e..."mente": Bases para a renovação e transformação da educação física. 20. ed. Campinas: Papirus, 2005a.

. O brasileiro e seu corpo. 10. ed. Campinas: Papirus, $2005 \mathrm{~b}$.

MELO, V. A. História da Educação Física e do Esporte no Brasil: panorama e perspectivas. 2. ed. São Paulo: Ibrasa, 1999. 
Thiago Elias Merlo

Núcleo de Educação Física/UCB

Sérgio Ferreira Tavares

Núcleo de Educação Física/UCB 